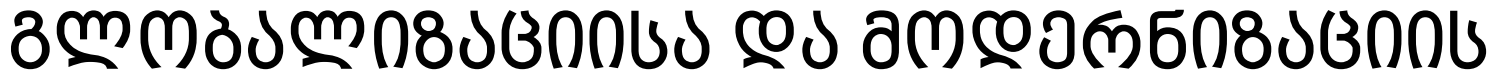

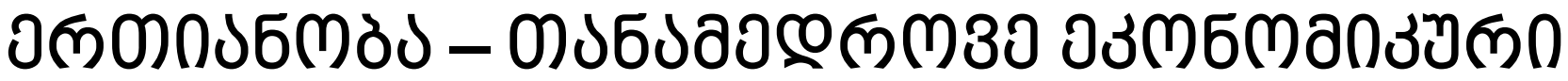

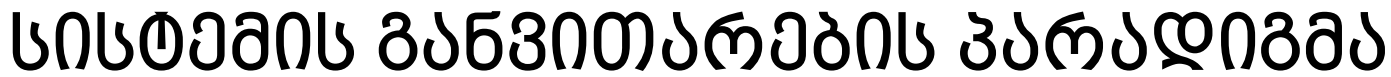

https://doi.org/10.35945/gb.2016.02.002

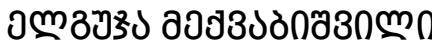

गзмбmanzol

○З

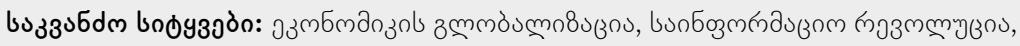

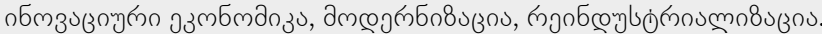

\section{0}

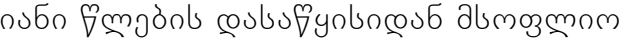

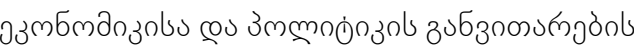

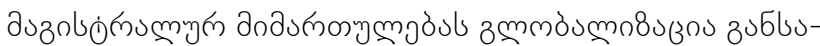

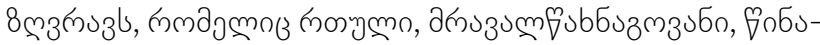

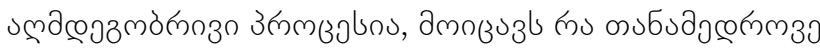

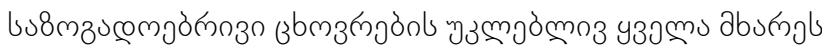

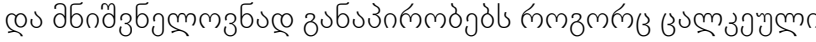

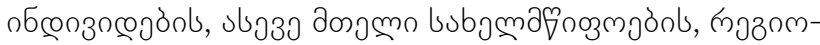

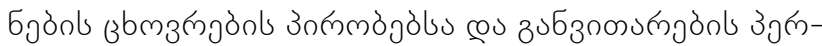

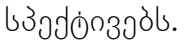

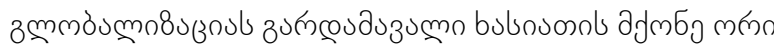

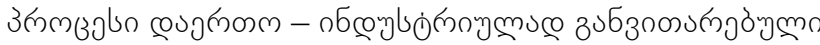

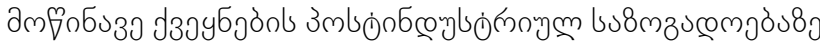

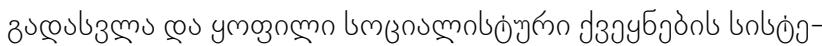

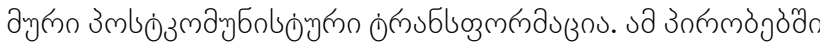

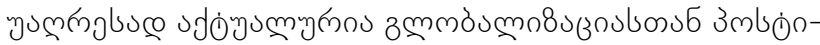

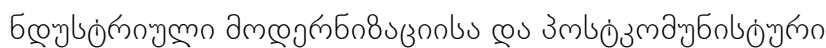

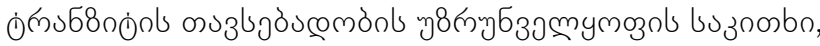

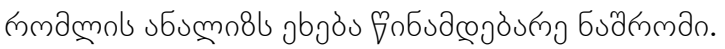

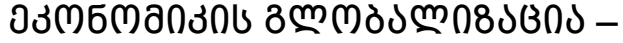

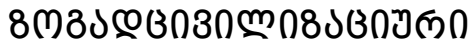

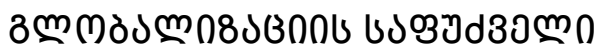

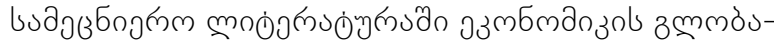

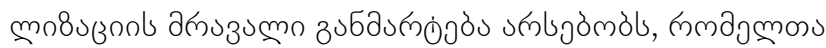

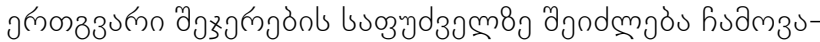

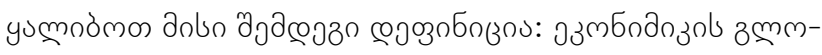

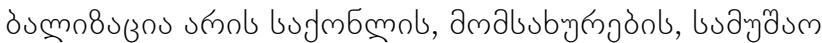

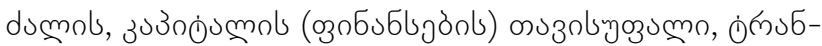

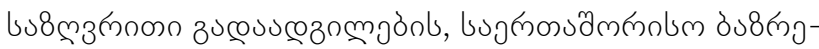

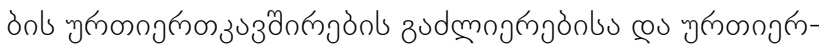

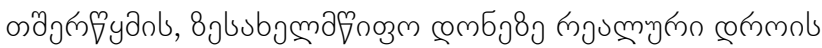

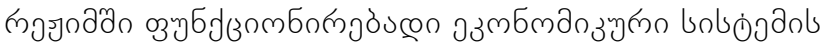

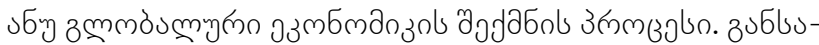

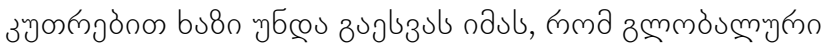

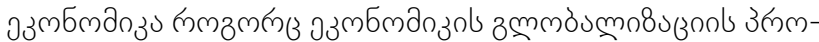

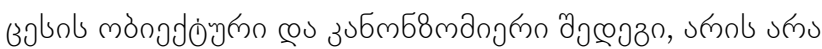

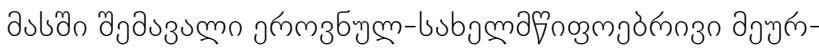

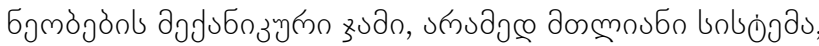

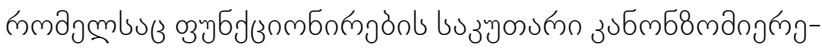

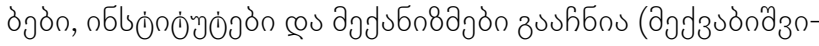

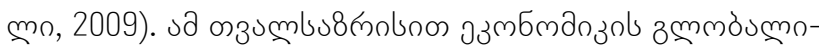

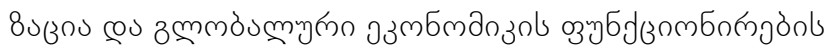

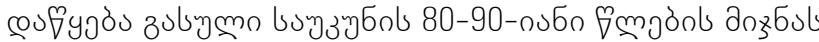

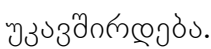

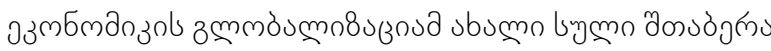

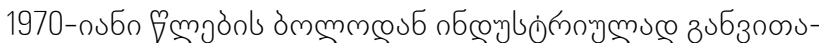

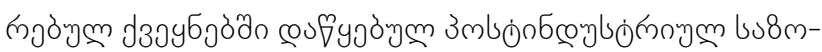

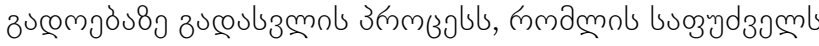

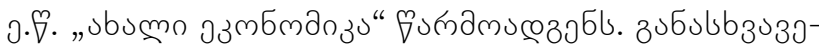

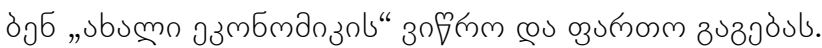

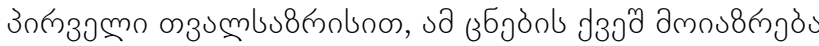




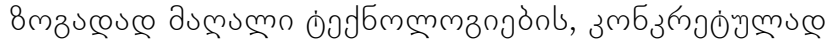

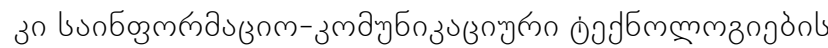

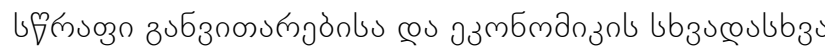

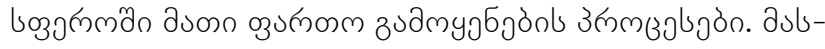

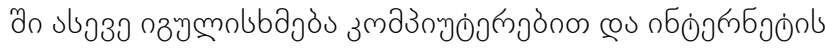

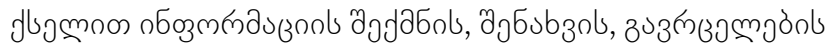

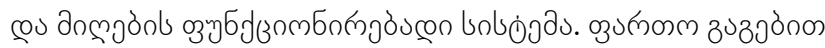

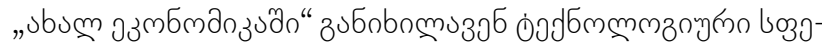

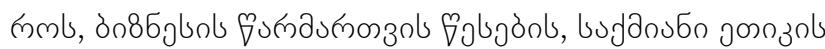

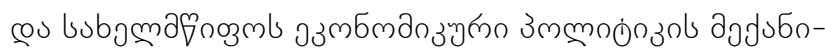

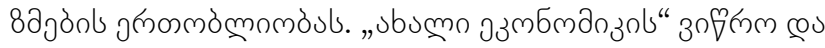

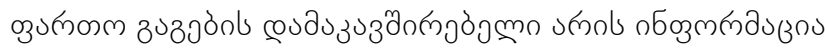

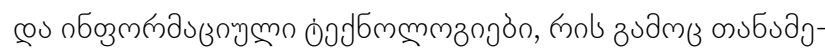

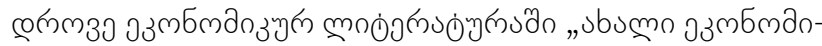

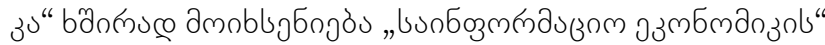

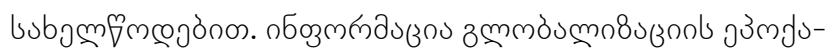

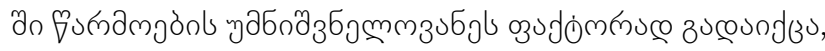

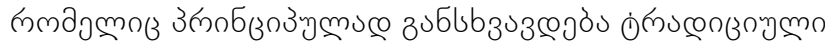

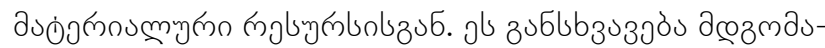

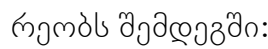

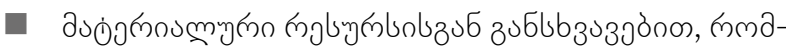

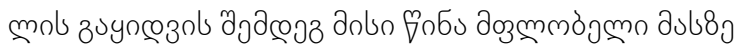

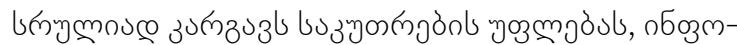

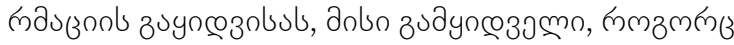

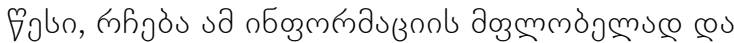
ymzomonzol yjydmos dnbo bymubumn zuynূ̧u

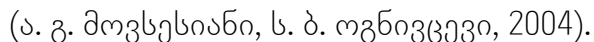

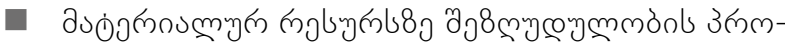

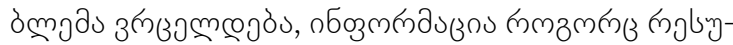

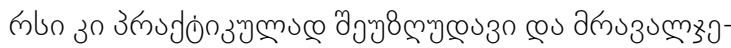
muson zudmyjбjònlomzols zumzantos.

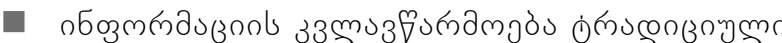

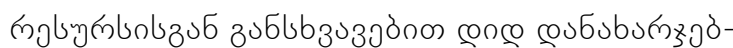

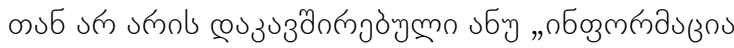

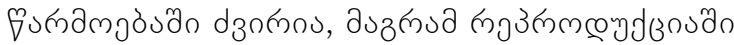

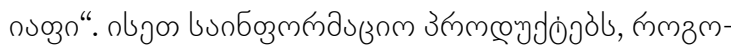

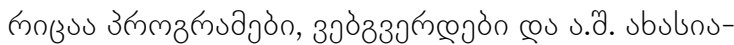

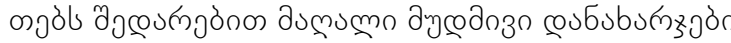

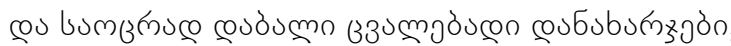

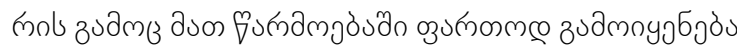

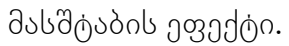

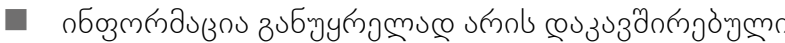

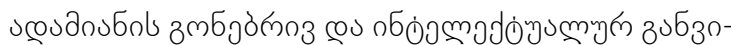

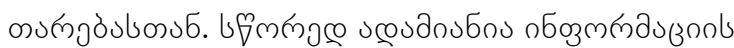

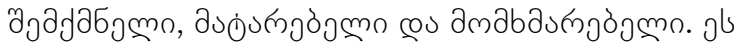

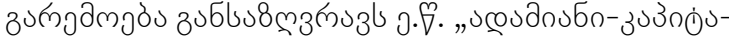

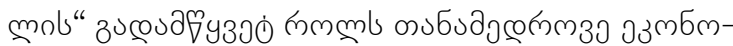

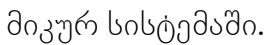

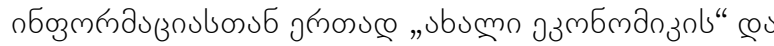

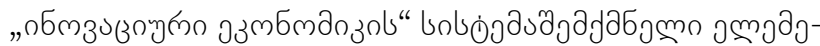

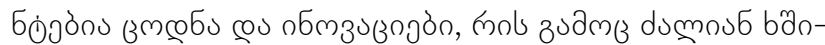

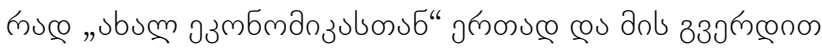

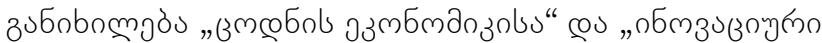

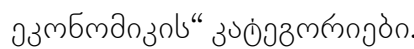

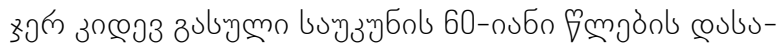

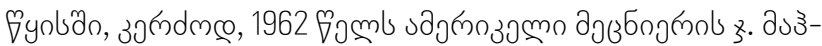

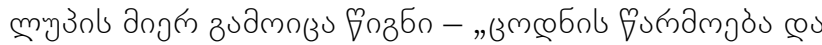

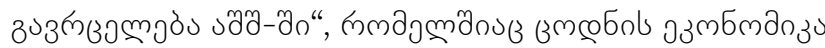

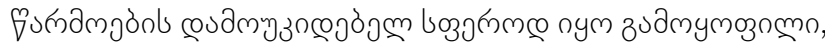

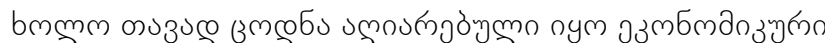

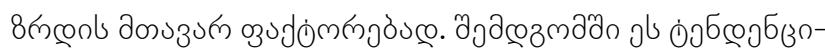

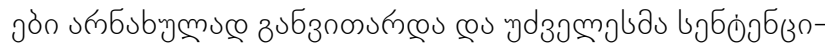

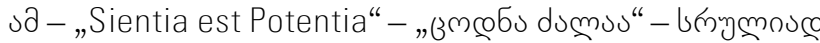

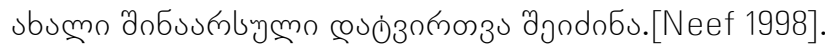

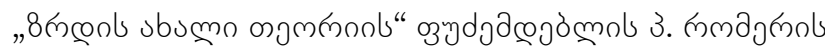

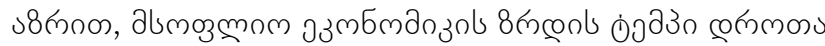

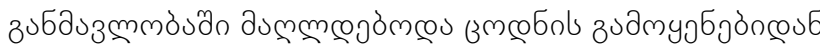

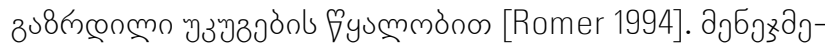

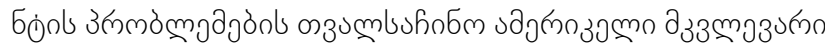

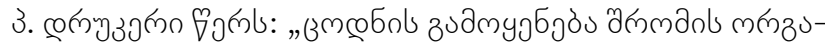

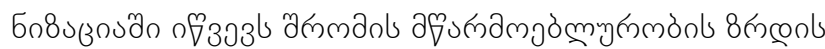

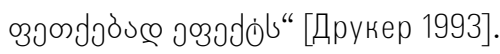

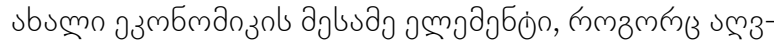

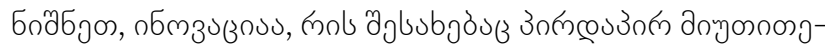

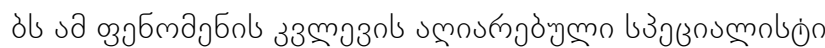
๓n. umzumon [Alkaly 2003].

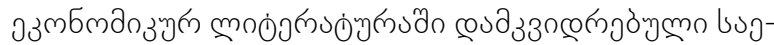

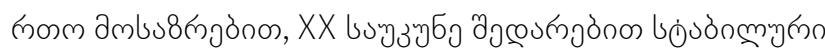

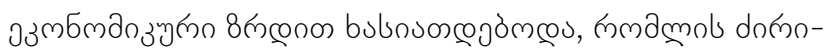

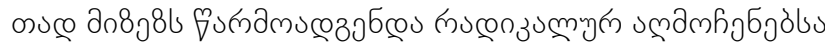

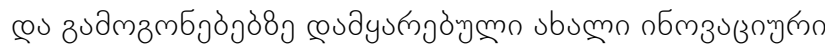

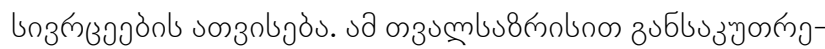

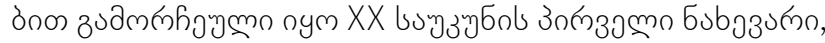

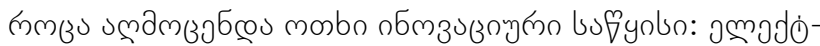

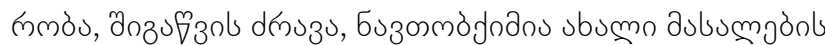

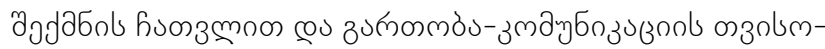

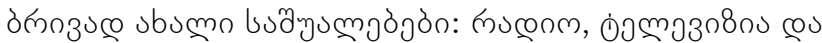

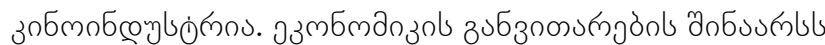
zublus 8 लूз

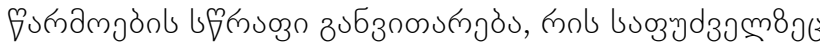




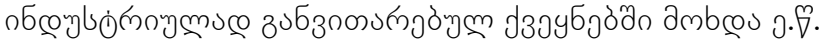

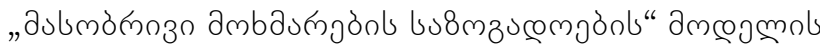

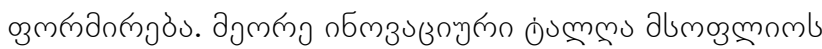

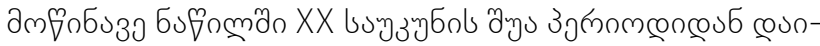

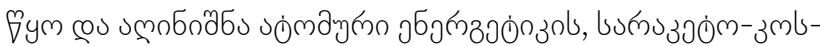

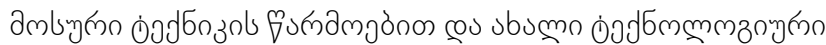

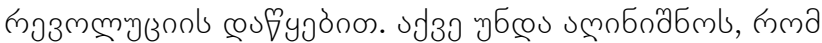

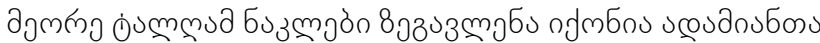

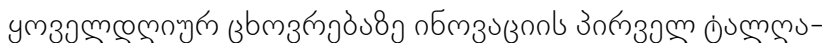

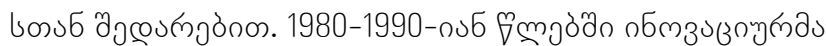

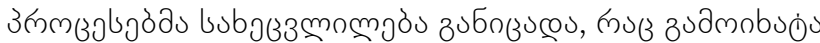

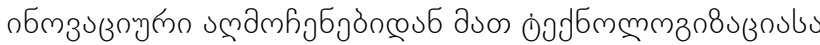

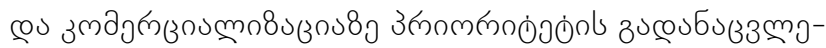

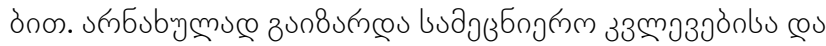

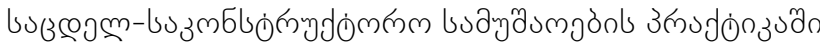

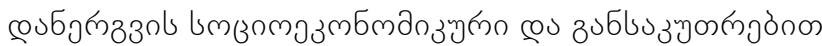

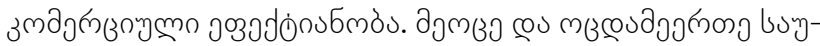

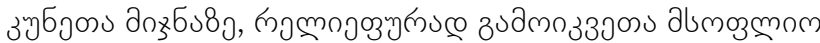

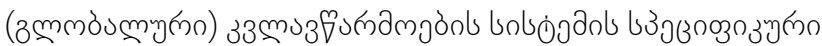

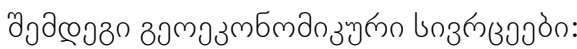

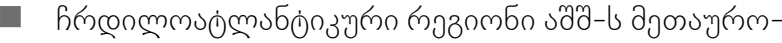

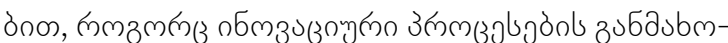

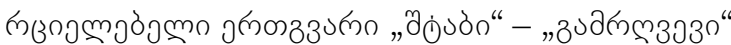

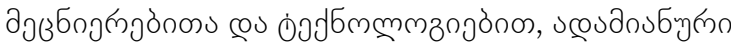

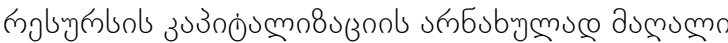

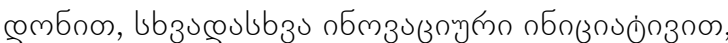

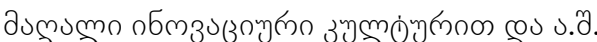

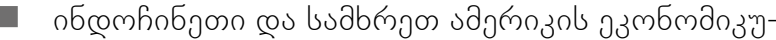

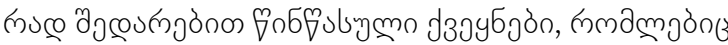

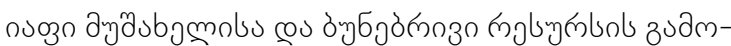

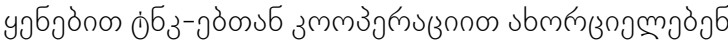

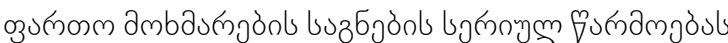
cos oflu3m的安l.

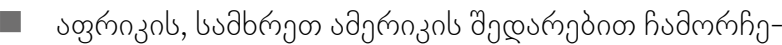

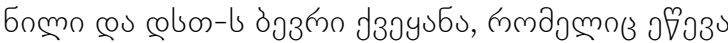

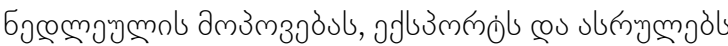

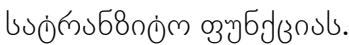

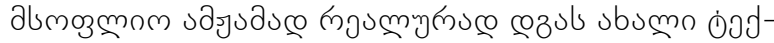

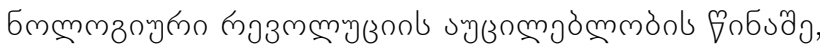

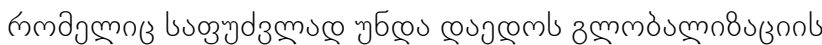

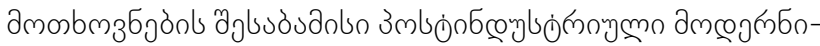

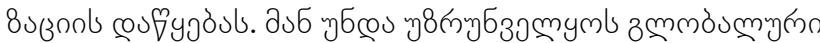

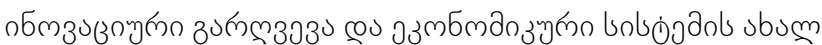

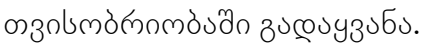

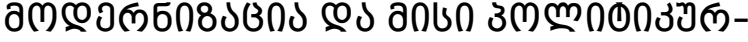 озмбмапзупก ащзобомก}

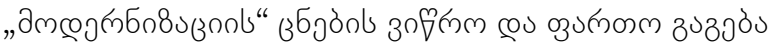

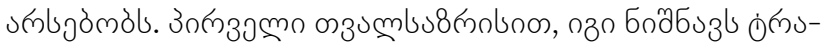

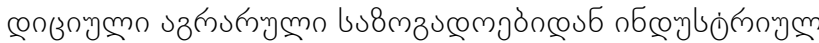

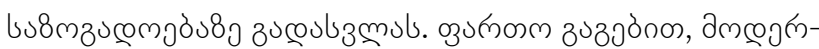

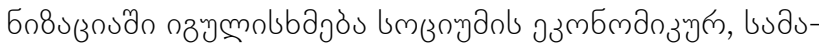

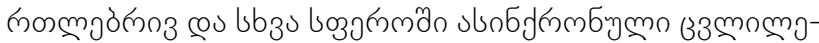

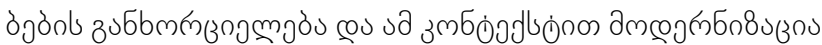

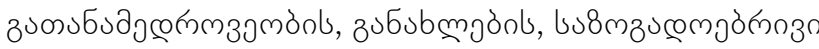

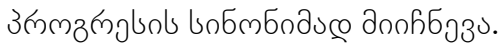

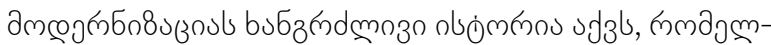

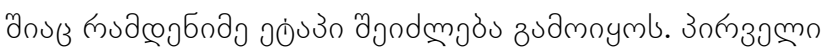

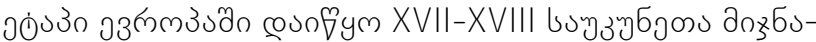

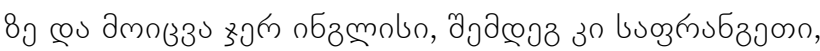

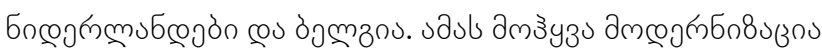

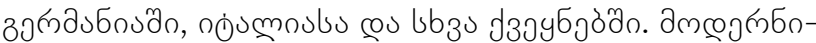

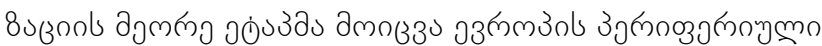

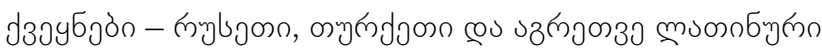

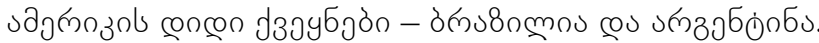

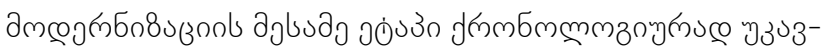

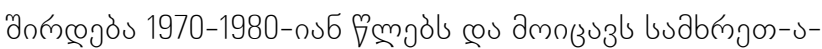

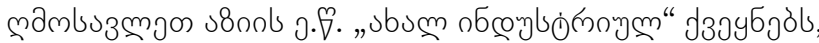

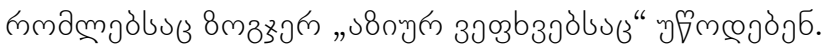

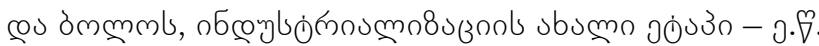

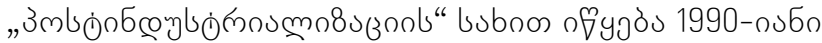

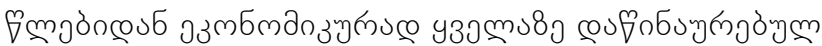

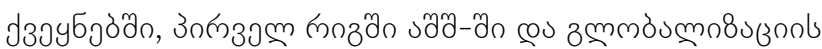

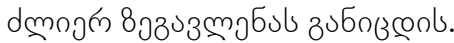

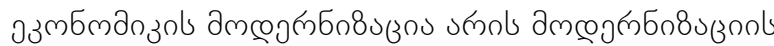

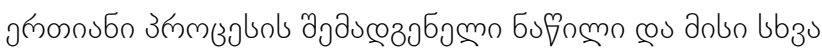

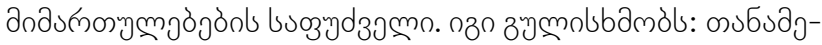

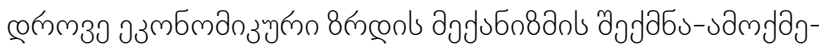

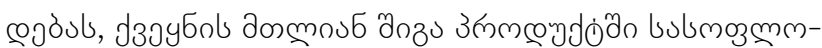

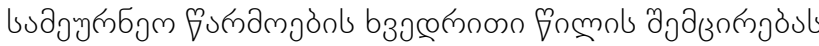

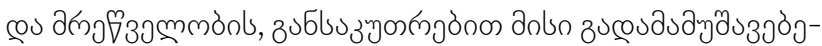

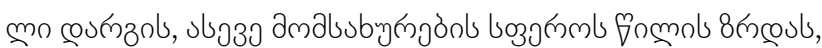

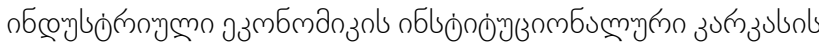

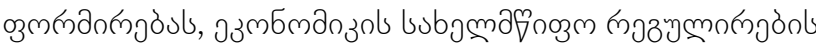

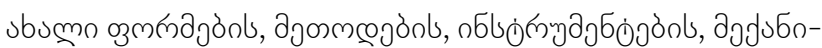

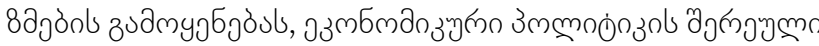

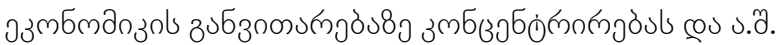

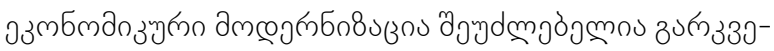

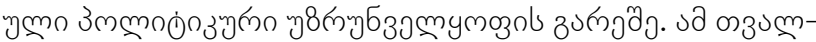




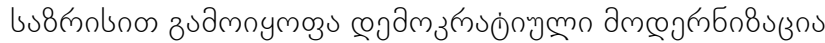

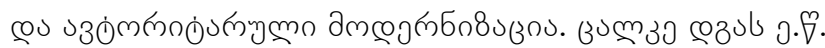

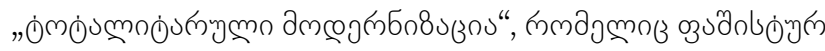

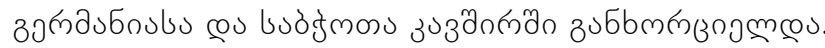

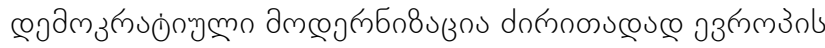

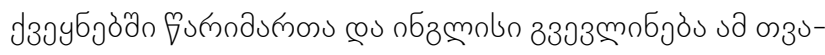

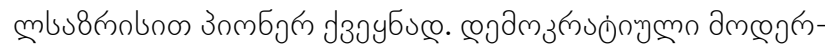

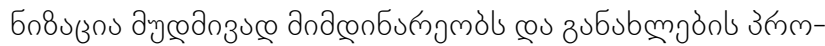

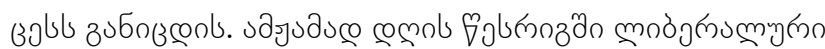
( (

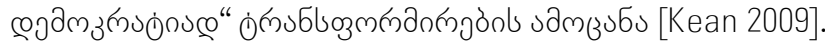

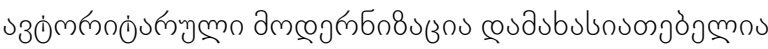

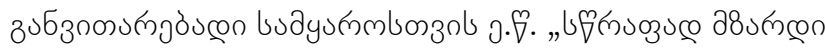

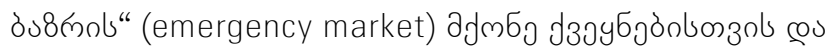

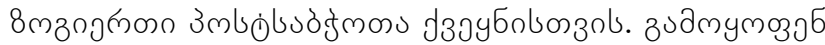

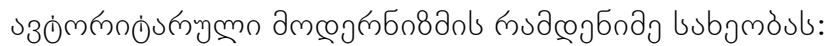

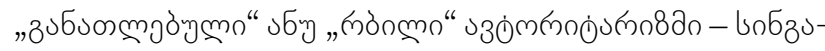

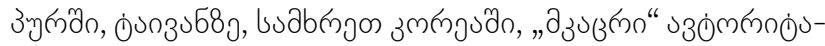

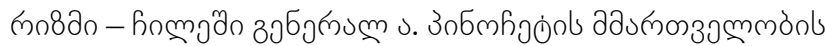

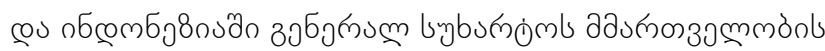

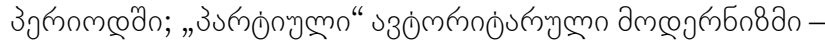

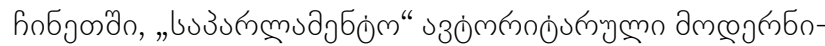

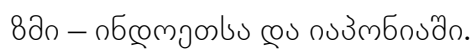

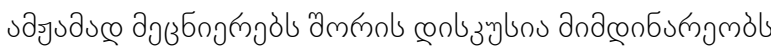

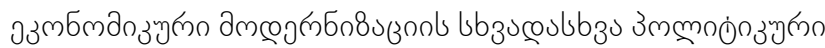

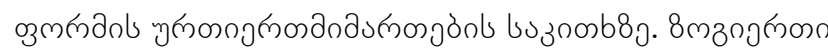

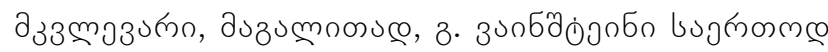

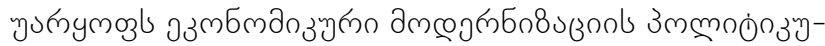

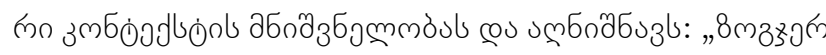

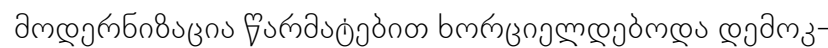

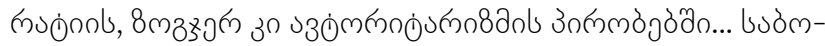

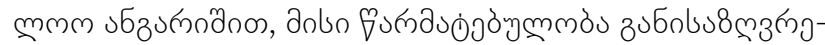

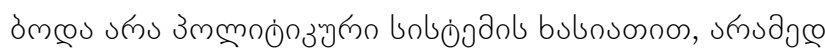

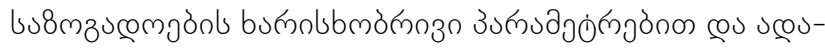

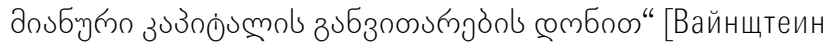

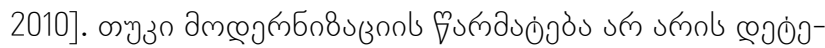

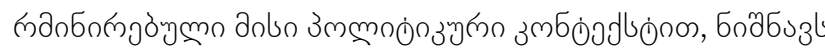

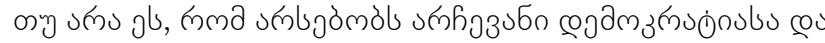

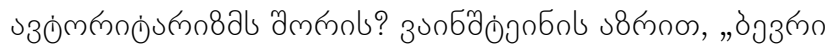

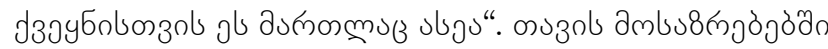

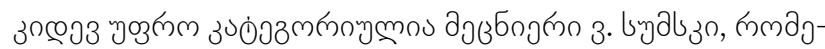

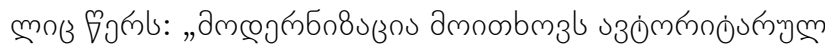

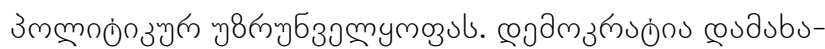

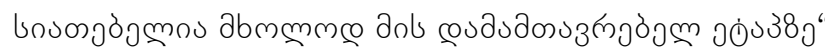

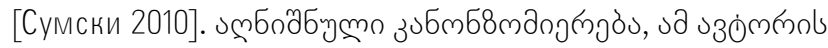

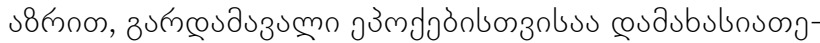

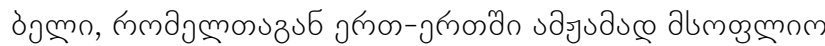

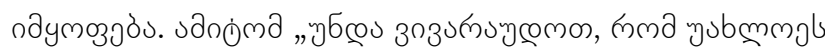

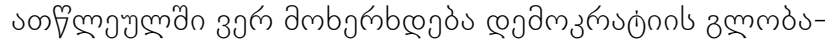

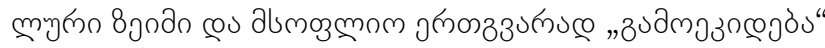

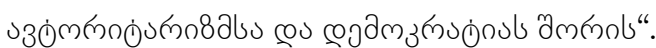

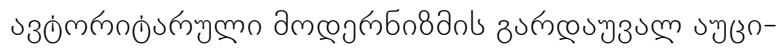

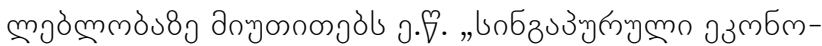

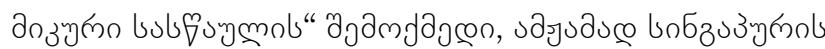

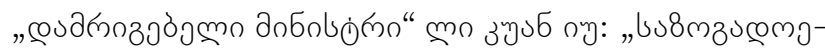

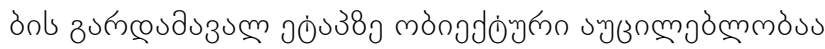

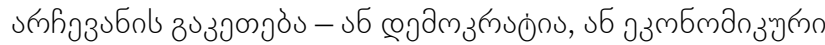

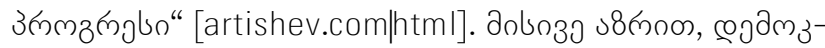

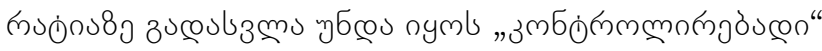

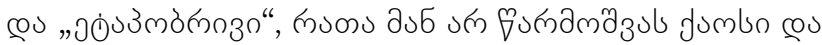
उபர்பர்கூmoூs.

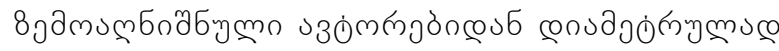

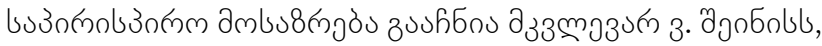

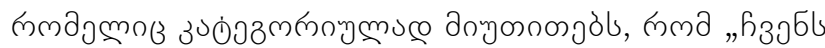

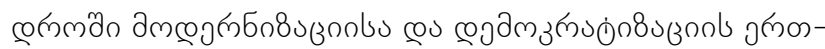

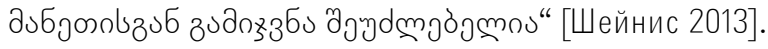

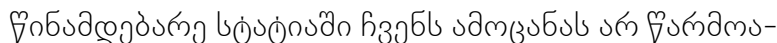

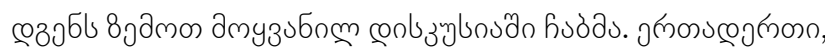

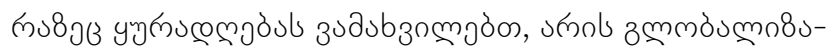

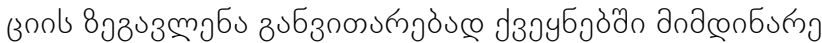

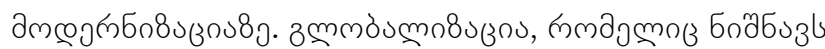

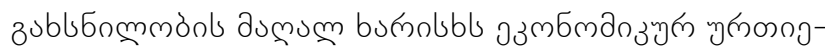

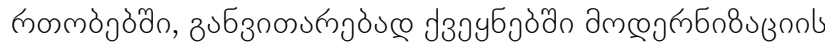

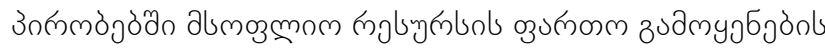

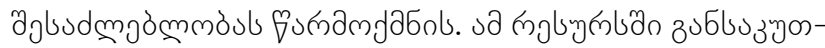

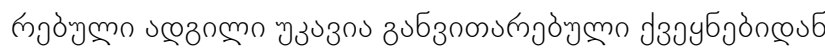

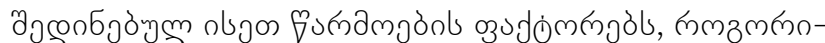

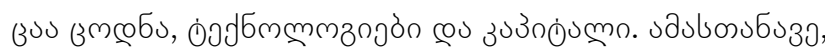

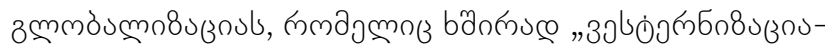

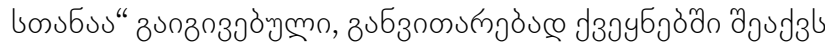

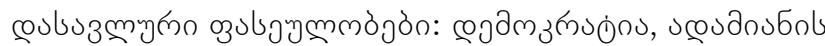

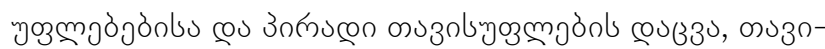

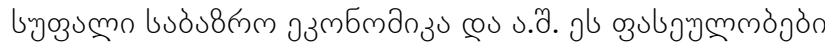

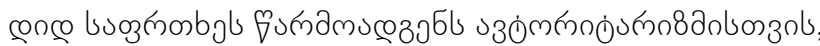

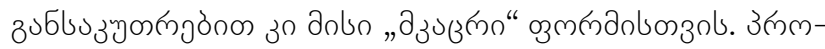

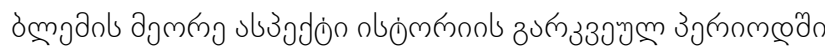

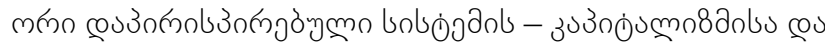

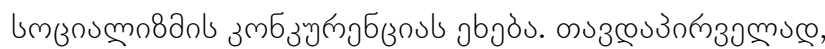

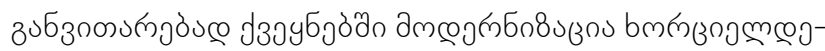

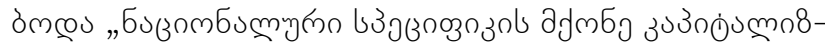




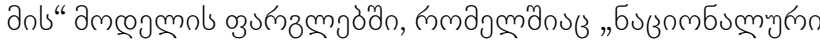

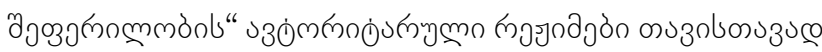

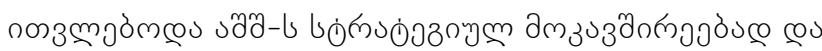

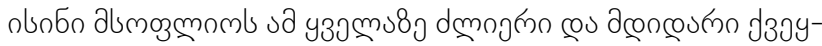

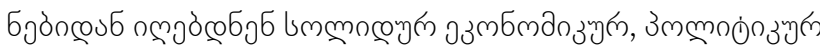

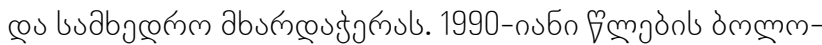

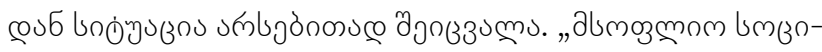

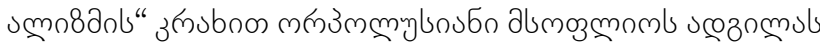

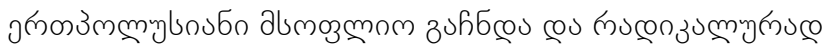

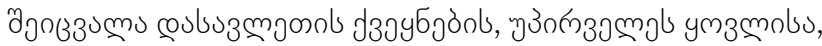

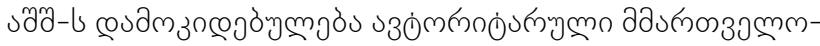

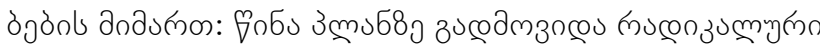

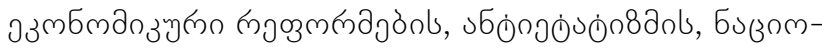

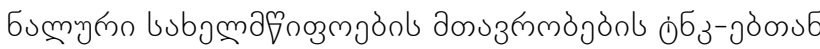

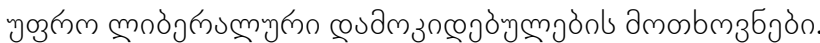

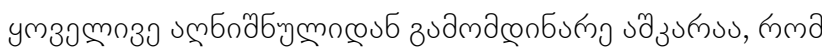

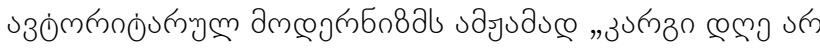

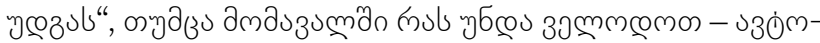

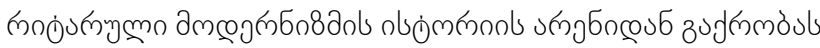

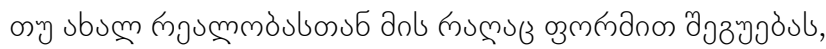

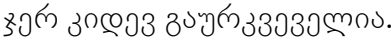

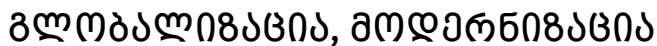

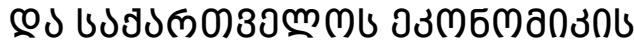

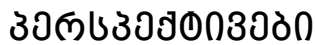

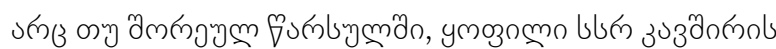
a

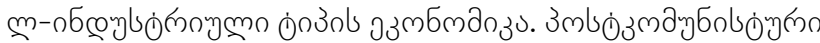

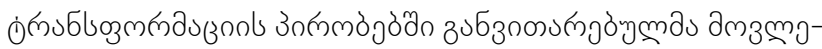

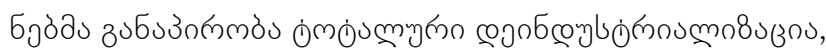
umogmols ajyn

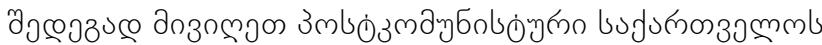

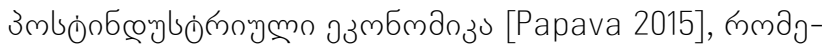

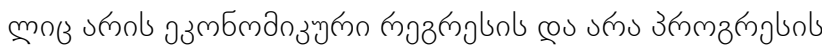
५nӘठ̀mmm.

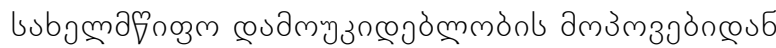

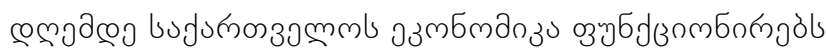

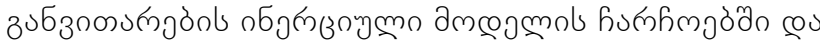

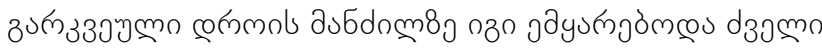

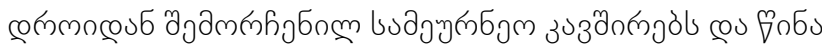

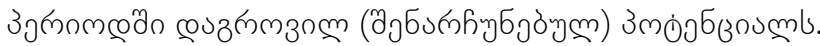

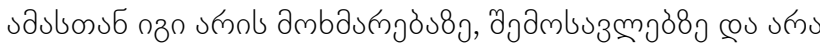

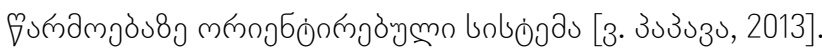

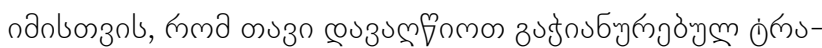

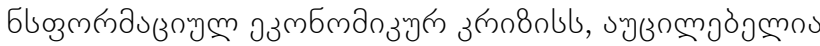

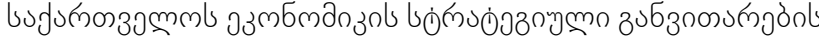

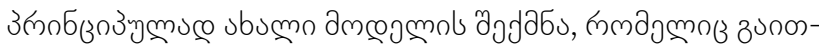

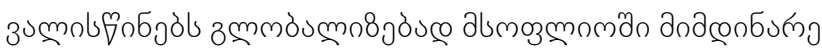
उलm(зjl)

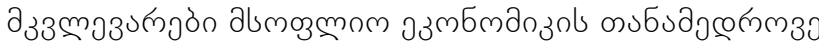

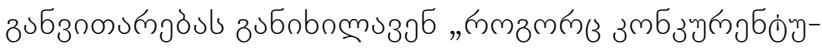

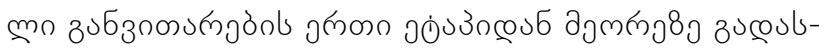

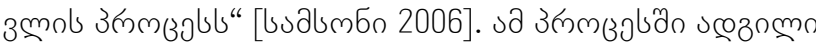

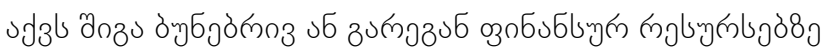

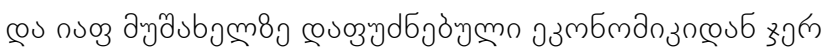

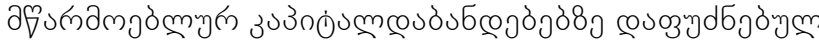

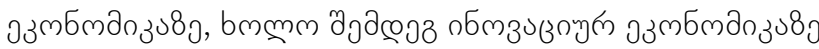

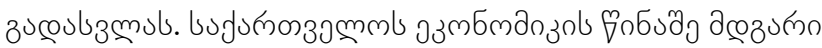

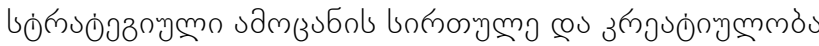

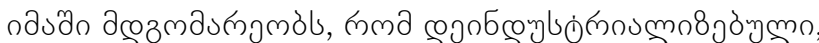

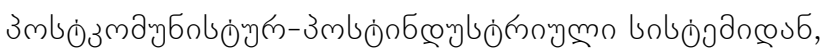

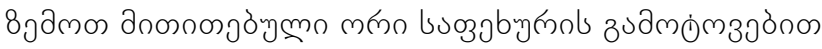

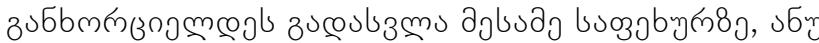

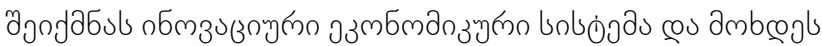

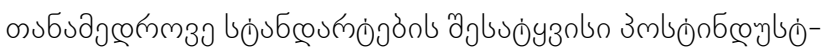

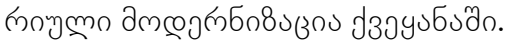

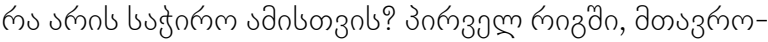

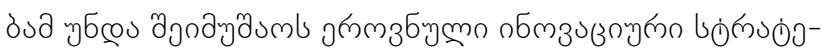

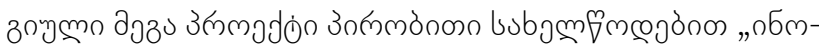

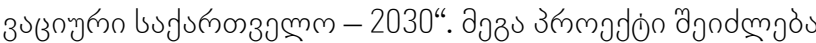

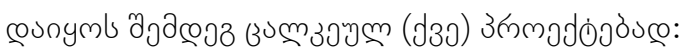

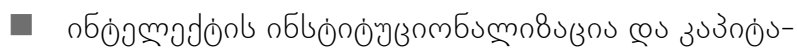
mo8०3००;

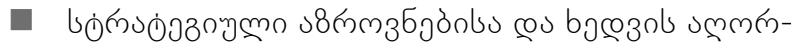

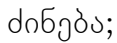

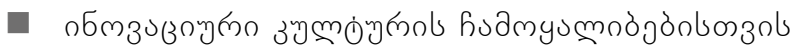

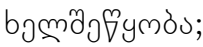

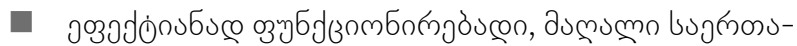

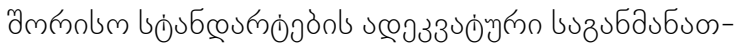

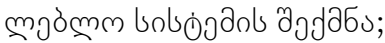

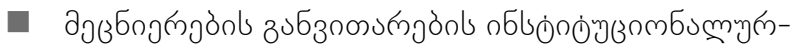

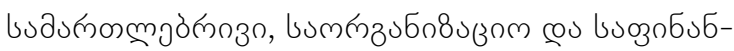

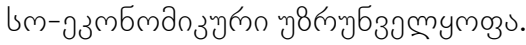

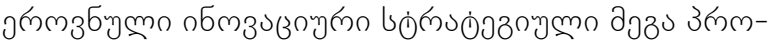

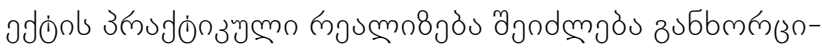

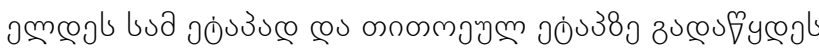

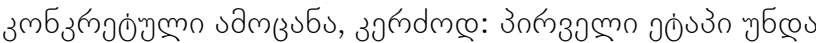

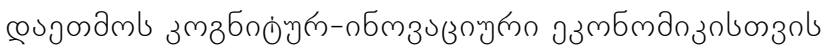

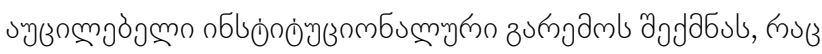

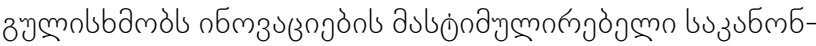




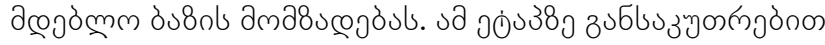
абпаз

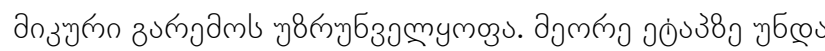

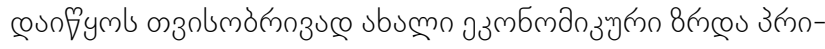

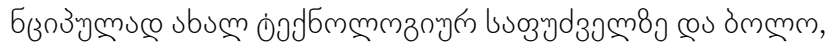

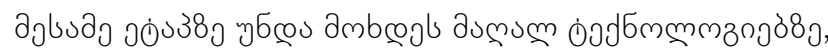

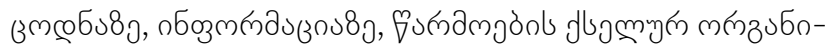

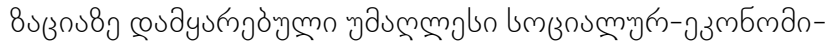

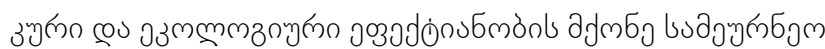

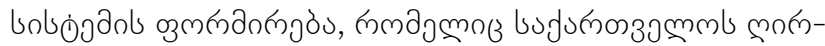

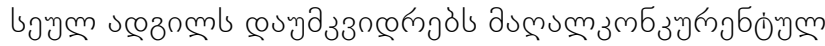

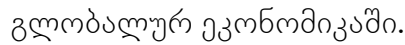

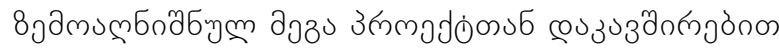

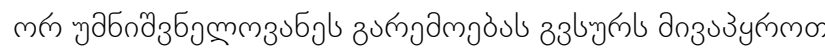

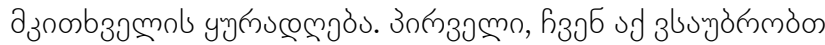

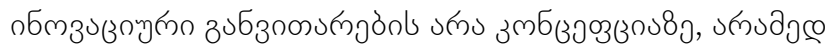

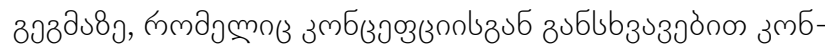

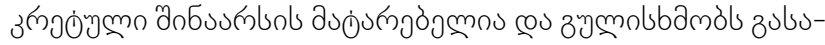

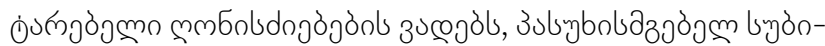

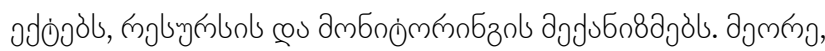

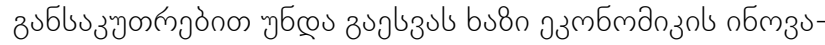

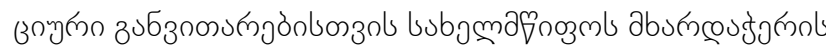

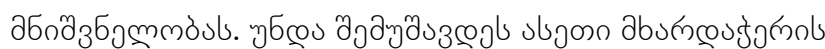

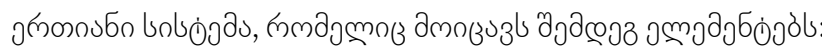

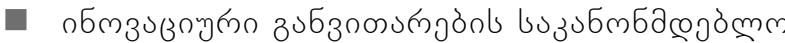

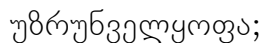

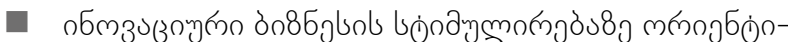

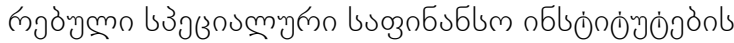

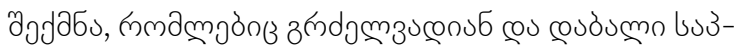

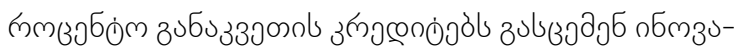

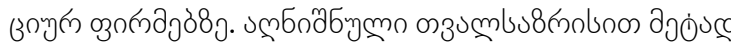

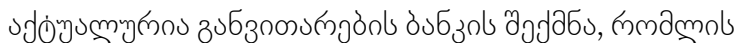
озचб

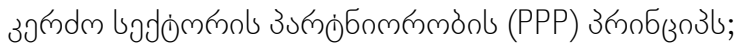

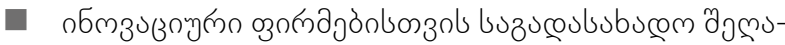

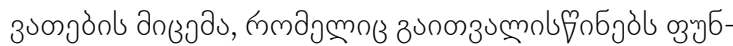

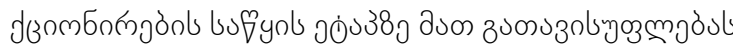

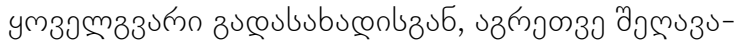

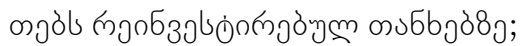

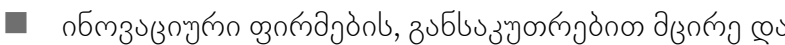

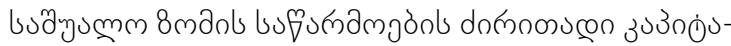

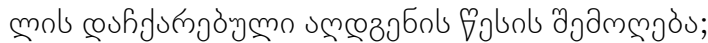

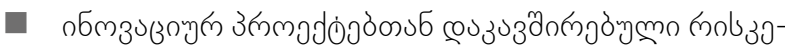

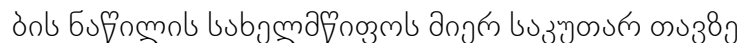
usgos;

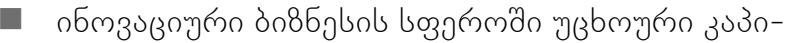

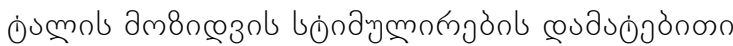

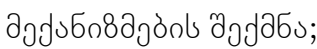

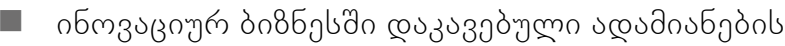

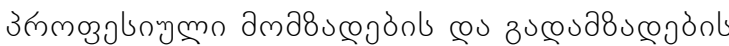

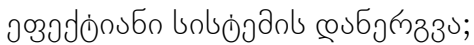

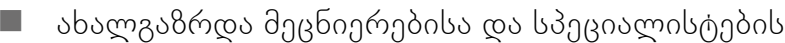

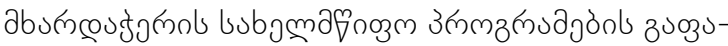
mosmgos;

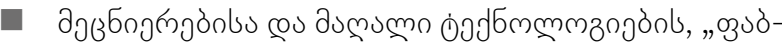

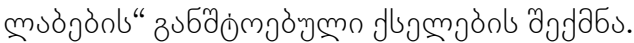

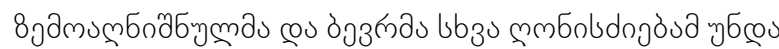

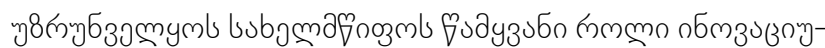

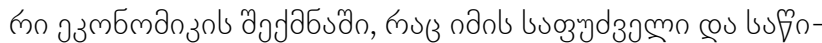

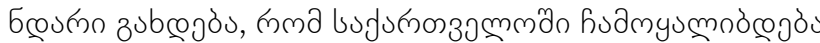

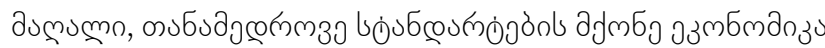

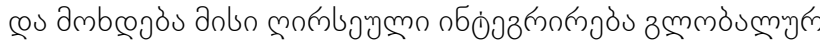
јзмбмдпзидп.

\section{হ⿺⿻一𠃋3}

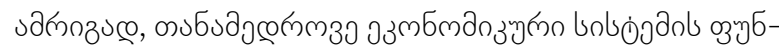

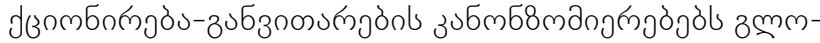

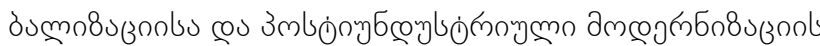

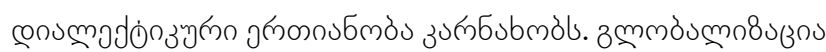
s

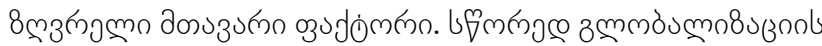

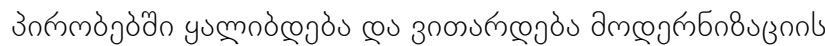

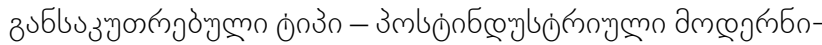

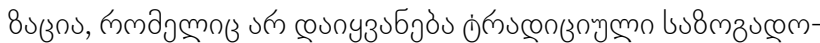

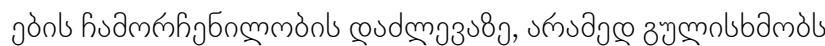

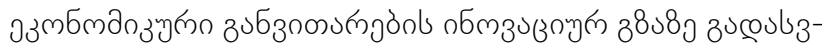

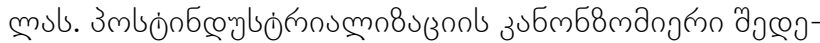

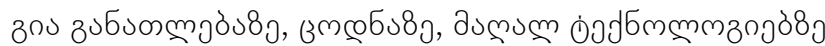

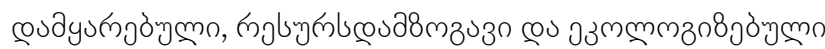

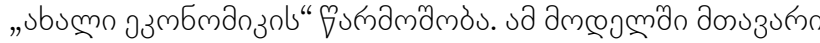

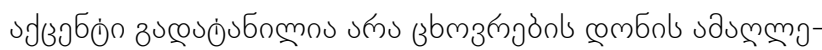

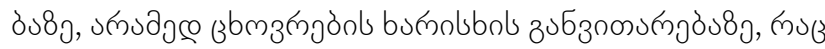

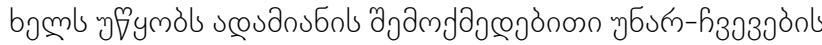

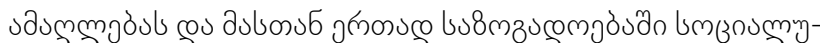

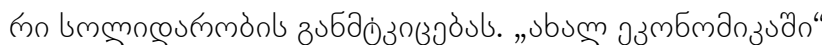

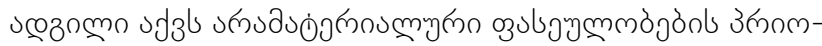

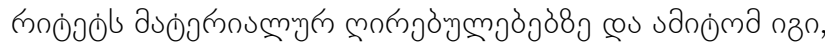

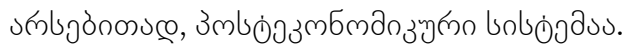

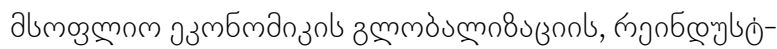

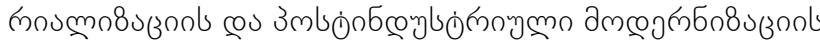




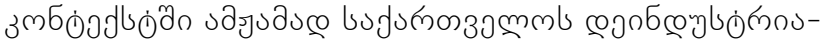

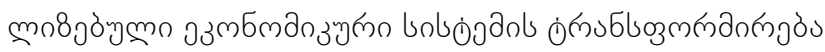

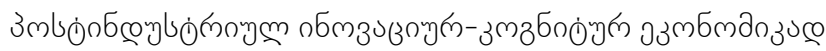

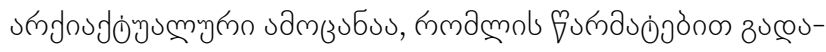

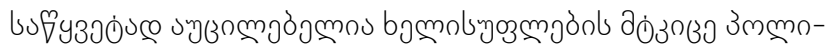

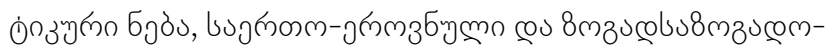

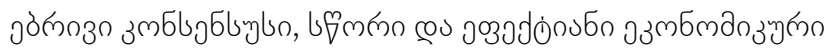

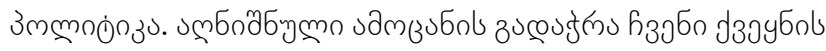

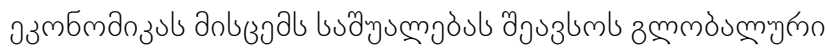

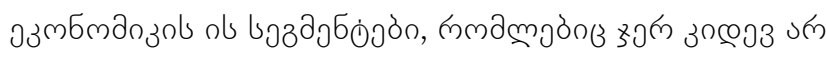

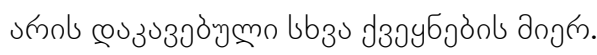

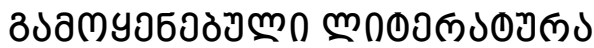

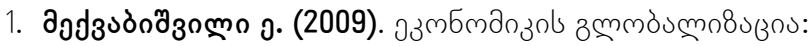

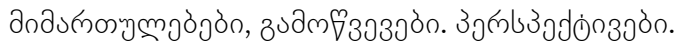

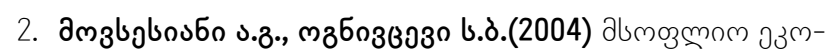
Бмдазо.
3. Neef j. ced.),(1998). The knowledge Economy. Boston.

4. Romer P. M. The Origins of Endogenous Growth. The Journal of Economic perspectives. 8(1). Pp.5-6.

5. Друкер П. (1993). Постэкономическое обшество.

6. Alkaly R.(2003). The New Economy. N.Y.

7. Kean j.(2009). Life and Death of Democracy. L.

8. artishev.com|html

9. Papava V. (2015). Necroeconomics of Post-soviet PostIndustrialism and the Model of Economic Development of Georgia and Russia.

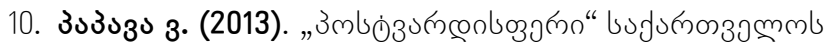

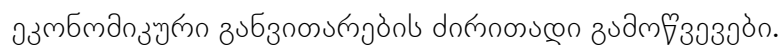

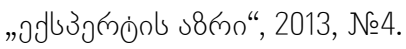

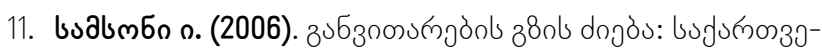

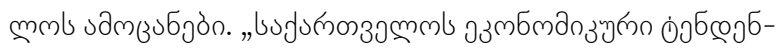

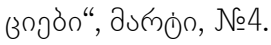

\title{
Unity of Globalization and Modernization - The Modern Economic Development Paradigm
}

https://doi.org/10.35945/gb.2016.02.002

\author{
Elguja Mekvabishvili \\ Doctor of Economic Sciences, \\ Professor of Ivane Javakhishvili Tbilisi State University Head of Theoretical \\ Economy Department
}

Key words: economic globalization, information revolution, innovative economic, modernization.

\footnotetext{
$\mathrm{T}$
} he paper deals with the relationship between the economy globalization and post-industrial modernism; justifies Georgia's strategic economic development's main direction: transition from deindustrialized post-communist economic system to the post-industrial knowledge economy and taking the decent place in the global economy 